\title{
PROCESSO DE GESTÃO ESTRATÉGICA EM UNIVERSIDADES PRIVADAS: UM ESTUDO DE CASOS
}

\author{
STRATEGIC MANAGEMENT PROCESS \\ IN PRIVATES UNIVERSITIES: A CASES STUDY
}

Recebido em 01.02.10 / Aceito em 27.07.10

Daniela Martins Diniz e José Marcio de Castro $^{2}$

\begin{abstract}
Resumo
O objetivo deste artigo é descrever e compreender como a Gestão Estratégica (GE) é desenhada, implementada e monitorada em universidades privadas. A análise dos dados revelou quais os fatores que afetam o processo de GE nessas universidades, suas características, os atores envolvidos no processo e, finalmente, a relação entre planejamento e desempenho. Os resultados indicam que em duas universidades estudadas (casos A e B) a GE é um processo consolidado e foi concebido para se desenvolver uma visão de futuro e auxiliar as organizações a lidarem com os desafios ambientais. Em contraste, no terceiro caso (C), os resultados indicam que a GE não se encontra ainda no mesmo nível de maturidade dos casos relatados anteriormente.

Palavras-chave: Gestão Estratégica. Formulação. Implementação. Controle de Estratégias. Universidades Privadas.

1 Bacharel em Administração pela Pontifícia Universidade Católica de Minas Gerais (PUC-MG). E-mail: danidiniz09@yahoo.com.br

2 Doutor em Administração/FEA/USP. Professor da PUC-MG. E-mail: josemarcio@pucminas.br
\end{abstract}




\begin{abstract}
The aim of this article is to describe and understand how Strategic Management is designed, implemented and monitored in private universities. The data analysis has revealed which factors have affected the Strategic Management process in these universities, its characteristics, the actors involved in this process and, finally, the relationship between planning and performance. The results have also shown that in two universities (cases A and B) their Strategic Management is already a mature process, which was designed in order to create a vision of the future and help both universities to deal with environmental pressures. By contrast, the third case (C) revealed that its Strategic Management has not reached yet the same level of maturity observed in the other two cases.
\end{abstract}

Universities.

Keywords: Strategic Management. Formulation. Implementation and Control of Strategies. Privates

\title{
1. INTRODUÇÃO E OBJETIVOS
}

O ambiente externo tem influência decisiva sobre a maneira como as organizações são estruturadas e gerenciadas (BURNS; STALKER, 1961; LAWRENCE; LORSCH, 1973; THOMPSON, 1967). Muito dessa influência é determinada pela percepção de incerteza que os gestores têm a respeito do ambiente, ou seja, pela incapacidade do indivíduo em prever algo de maneira precisa. (MILLIKEN, 1987). Se o ambiente afeta a organização, esta, por sua vez, se vê compelida a remodelar suas estratégias e, em decorrência, suas estruturas em função das contingências. (CHANDLER, 1962; EMERY; TRIST, 1965; LAWRENCE; LORSCH, 1973).

A universidade, como um tipo particular de organização (MINTZBERG, 1995), inserida neste cenário imprevisível, se vê, muitas vezes, obrigada a repensar o seu modo de atuação com foco no curto prazo e a se conscientizar quanto à importância das questões estratégicas.

O ambiente das organizações da educação superior tem se alterado sobremaneira, tanto em nível de macroambiente, como em nível do ambiente tarefa. No nível macroambiental, fatores de natureza legal e tecnológica mudaram muito nos últimos anos (as regulamentações legais sobre o ensino superior, como a Lei de Diretrizes e Bases da Educação Nacional, o ensino a distância, dentre outras alterações). No ambiente tarefa, podem-se destacar a expansão da concorrência, decorrente de uma política expansionista do ensino superior, e as consequentes transformações nas regras de competição no setor da educação.

Tais mudanças se refletem na realidade das instituições de ensino superior que, mais recentemente, tem constatado uma queda expressiva da relação candidato/vaga e, em decorrência, o excesso de vagas ociosas, a pressão sobre os valores das mensalidades e o esforço extra para garantir sustentabilidade financeira. Neste contexto, torna-se importante compreender como as universidades têm se posicionado estrategicamente para enfrentar essa dinâmica competitiva.

Além do impacto que o ambiente exerce na universidade, cabe destacar que esta é uma instituição peculiar e diferente de outras organizações do setor industrial ou comercial. (MINTZBERG, 1995). Isto porque a universidade é caracterizada pela complexidade do trabalho operacional e de suas atividades-fim (ensino, pesquisa e extensão), além de ser cenário de disputas entre atores de diversas áreas de conhecimento e de possuir objetivos ambíguos e desconexos. Essas características internas demandam o desenvolvimento de processos que articulem e integrem finalidades. Daí a relevância da gestão estratégica no contexto universitário.

Dado o ambiente em que opera a universidade e a sua importância para o cenário educacional, buscou-se, através deste estudo, descrever o processo de gestão estratégica no âmbito dessas instituições. Foram abordadas as etapas de formulação, de implementação e de controle e avaliação de estratégias.

Rev. Adm. UFSM, Santa Maria, v. 3, n. 3, p. 311-325, set./dez. 2010 
Os objetivos complementares ao propósito central descrito acima são: identificar os fatores que motivaram as universidades privadas a desenvolverem a gestão estratégica; descrever as características do processo; apontar os atores envolvidos e verificar se há relação factível entre a GE e o desempenho da instituição.

Em termos de contribuições, é importante ressaltar que apenas recentemente as instituições de ensino superior vêm sendo objeto de maior atenção em pesquisa no campo da gestão (BERTUCCI, 2000). Isto parece estar relacionado com a dualidade de papéis desse tipo de instituição, que pendula entre seus objetivos de ensino, pesquisa e extensão e a racionalidade de mercado que emerge em tempos atuais. Investigar tais instituições e sua gestão constitui-se num esforço relevante para entender como essas organizações tão peculiares têm utilizado os mecanismos racionais de gestão. Em segundo, se tal racionalidade parece uma realidade nessas organizações, conhecer como elas estão adotando as práticas de gestão, mais especificamente, a gestão estratégica, além de elucidar o seu modus operandi, permitirá, posteriormente, fazer comparações com outros tipos de organizações, como indústrias e empresas de serviços mais afeitas aos padrões de competição.

Para além dessa introdução, dos objetivos e contribuições da pesquisa, o artigo estabelece, na segunda parte, uma breve revisão teórica sobre a estratégia e o processo de gestão estratégica. Na terceira parte, apresenta-se a metodologia de pesquisa. Por último, discutem-se as evidências encontradas, as conclusões, bem como as limitações e sugestões de pesquisas futuras.

\section{REVISÃO DA LITERATURA}

\subsection{Estratégia: origem e conceitos}

A estratégia tem, cada vez mais, sido reconhecida como algo intrínseco à gestão das empresas e constituído foco de inúmeras pesquisas, dada a sua importância indiscutível para o campo da Administração. A despeito da grande visibilidade que a gestão estratégica possui atualmente, os pensamentos sobre estratégia já existiam desde antes de Cristo, e os conceitos que fundamentam esta área das ciências gerenciais vêm evoluindo ao longo do tempo e agregando diversas perspectivas. (MINTZBERG; AHLSTRAND; LAMPEL, 2000).

No passado, o termo estratégia significava as alternativas e manobras que os generais propunham nos combates militares, visando sobressair sobre inimigos de guerra (MOTTA, 2002). $\grave{A}$ medida que as sociedades expandiam e as batalhas se tornavam mais complexas, generais testavam concepções estratégicas, bem e mal-sucedidas, até que um conjunto de pressupostos começou a se formar. (QUINN, 2001).

A partir daí, múltiplos significados de estratégia surgiram. As pesquisas na área estabeleceram relações do conceito de estratégia com o ambiente (LAWRENCE; LORSCH, 1973), com a estrutura empresarial (CHANDLER, 1962), com os planos formais (ANSOFF, 1983), com as forças setoriais (PORTER, 2001), com o processo de aprendizagem organizacional. (QUINN; VOYER, 2001).

Atentos a essa diversidade, Mintzberg, Ahlstrand e Lampel (2000) criaram dez escolas do pensamento da estratégia, que retratam a evolução do conceito de estratégia e os principais modelos de formulação, considerando-se o período de 1960 a 1990. Enquanto algumas escolas declinaram, outras vêm ganhando espaço nas organizações.

As dez escolas da estratégia são subdivididas em três grandes grupos. O primeiro, de natureza prescritiva, está mais preocupado em como a estratégia deve ser formulada e menos 
como de fato a mesma é concebida. Em outras palavras, o grupo prescritivo dá uma preferência ao olhar para o futuro em detrimento da visão retrospectiva. Esta perspectiva engloba as linhas do design, do planejamento e do posicionamento. (CHANDLER, 1962; ANSOFF, 1983; PORTER, 2001).

Em contraposição, o grupo descritivo apresenta o processo pelo qual a estratégia foi realmente concebida. Nessa abordagem, encontram-se as escolas empreendedora, cognitiva, do aprendizado, do poder, a cultural e a ambiental. (QUINN, 2001; BAUM, 1998). E, por fim, o último grupo engloba apenas uma escola, a configuração. Esta entende que o processo estratégico pode ser descritivo ou prescritivo, desde que seja adequado ao ambiente, ao ciclo de vida da organização, bem como às características internas da firma. (MINTZBERG; AHLSTRAND; LAMPEL, 2000).

A presente pesquisa se baseou nas premissas do grupo prescritivo, que presume que a estratégia é resultado de um processo planejado, controlado e consciente, denominado de administração estratégica, por Ansoff e McDonnell (1993), no Brasil, de planejamento estratégico, por Oliveira (1993), e de gestão estratégica, por Tavares (2000).

A administração estratégica consiste na definição de políticas, objetivos e ações, conscientemente elaboradas e que direcionam os rumos organizacionais (ANSOFF; McDONNELL, 1993; ANDREWS, 2001; QUINN, 2001; RUMELT, 2001; MINTZBERG, 2001). Nesse processo estratégico, é fundamental que haja consistência entre as ações dos indivíduos com os objetivos estabelecidos para a efetividade de estratégia. Em outras palavras, a administração estratégica consiste em produzir futuros desejados, que não serão alcançados se decisões adequadas não forem tomadas hoje. (ACKOFF, 1975).

Além de direcionar a ação dos indivíduos e gerar consistência interna, a gestão estratégica tem outra contribuição importante, qual seja: possibilita que a firma alcance o ajuste estratégico. (ANDREWS, 2001). Isto significa que, a partir de um processo de avaliação das forças externas e do ambiente interno, a organização consegue unir possibilidades externas com as suas competências internas. E, além disso, qualifica a organização a lidar mais facilmente com as pressões ambientais. (ACKOFF, 1975; ANDREWS, 2001). Nesses termos, Tavares (2000) conceitua o planejamento como um "conjunto de atividades planejadas e intencionais, estratégicas e organizacionais, que visa integrar a capacidade interna ao ambiente externo". (TAVARES, 2000, p. 33).

A gestão estratégica pode ser visualizada como um processo, ou seja, uma sequência de etapas articuladas entre si. As grandes fases desse processo formal são a formulação, a implementação e o controle e avaliação, detalhadas no próximo item. (ANSOFF; McDONNELL, 1993; OLIVEIRA, 1993; WRIGHT et al., 2000).

\section{O PROCESSO FORMAL DA ESTRATÉGIA: GESTÃO ESTRATÉGICA}

A formulação, primeira etapa da gestão estratégica, refere-se ao momento que a organização está planejando e decidindo o que fazer. Como resultado tem-se um conjunto de objetivos e estratégias direcionadas ao alcance da visão de futuro da organização. (ANDREWS, 2001). Entre as subatividades da formulação mais conhecidas estão: a realização de diagnósticos ambientais (externo e interno); o desenvolvimento da missão; o estabelecimento dos objetivos e das estratégias empresariais. (OLIVEIRA, 1991; TAVARES, 2000; WRIGHT et al., 2000; ANDREWS, 2001).

O diagnóstico do ambiente externo constitui uma das principais atividades de formulação estratégica como processo racional (ANDREWS, 2001). Isto, pois, a atividade organizacional 
está sujeita a influências externas imprevistas e, muitas vezes, incontroláveis (LAWRENCE; LORSCH, 1973). Sendo assim, é fundamental que a organização identifique e monitore as forças ambientais e crie condições eficazes para operar no ambiente. (TAVARES, 2000).

Nesses termos, a análise ambiental consiste em mapear as forças competitivas e estudar a relação que a empresa estabelece com o ambiente, em termos de oportunidades e ameaças (ANDREWS, 2001; WRIGHT et al., 2000; OLIVEIRA, 1991; TAVARES, 2000). Esta avaliação compreende duas instâncias de análise, quais sejam: o macroambiente e o ambiente tarefa (setor de negócios). O macroambiente engloba as forças que a empresa não tem o poder de interferir e que, de certa forma, regulam as decisões da empresa, dentre elas: demográficas, tecnológicas, políticas, econômicas etc.

O ambiente tarefa, por sua vez, envolve as forças mais próximas da firma e que intervêm de forma mais específica nas suas atividades. (WRIGHT et al., 2000). Entre os públicos que se relacionam mais diretamente com as organizações estão os fornecedores, compradores e concorrentes. A análise do ambiente tarefa consiste em mapear as forças competitivas e verificar como estas podem interferir nas atividades empresarias. Posteriormente, deve-se identificar um posicionamento no setor onde a organização possa influenciar os fatores competitivos a seu favor. (PORTER, 2001).

A despeito da relevância da avaliação externa, é fundamental que a organização também se dedique na análise interna, uma vez que antes de ser feita uma escolha estratégica os pontos fortes e fracos devem ser avaliados juntamente com as oportunidades ambientais (ANDREWS, 2001). Nestes termos, o diagnóstico interno "cuida da adequação do modelo organizacional ao que se pretende desenvolver em face das oportunidades e ameaças ambientais". (TAVARES, 2000, p. 263). Ou seja, seu objetivo é avaliar se a empresa possui capacidade de aproveitar e potencializar as oportunidades e minimizar as ameaças. (ANDREWS, 2001).

Subsequentemente aos estudos ambientais, a organização deve se engajar na construção da sua missão, ou seja, na definição da sua razão de ser, do seu papel na sociedade e do que ela pode oferecer aos seus stakeholders. A missão vai criar um senso comum para a ação dentro da organização. (OLIVEIRA, 1993; WRIGHT et al., 2000).

Depois de efetuados os diagnósticos ambientais e de definida a missão da organização, os indivíduos devem trabalhar na proposição dos objetivos. São os alvos a serem alcançados e, que para tanto, a organização deve concentrar seus esforços na mesma direção (OLIVEIRA, 1991; WRIGHT et al., 2000; TAVARES, 2000). É importante converter os objetivos em desempenhos específicos e quantificáveis, ou seja, traduzi-los em metas, facilitando o controle e o comprometimento com os resultados pretendidos. (ACKOFF, 1975).

A última etapa da formulação é a definição das estratégias, que consiste em refletir sobre qual o caminho mais eficaz para alcançar as metas propostas. As estratégias "estabelecem o que fazer para pôr em prática os objetivos estratégicos no horizonte de planejamento e, simultaneamente, reforçar a posição competitiva". (TACHIZAWA; ANDRADE, 2006, p. 102). A seleção do curso de ação mais eficiente deve considerar aquele que combinar tempo, recursos, custos e riscos da forma mais sinérgica. (TAVARES, 2000).

Formulados os objetivos e as estratégias, a organização deve se engajar na execução dos planos desenvolvidos, uma vez que "a chave do êxito de uma gestão estratégica - a combinação entre estratégia e gestão - está em sua operacionalização". (TAVARES, 2000, p. 360). Mesmo que o processo de formulação tenha sido bem-sucedido, a estratégia pode fracassar, se não for eficientemente implementada. (WRIGHT et al., 2000; ANDREWS, 2001).

A implementação consiste em fazer com que a empresa comporte-se de acordo com os objetivos estabelecidos e, para tanto, requer o desdobramento do plano estratégico em proje- 
tos táticos e operacionais, de forma a incorporar as tarefas rotineiras da organização. Esses programas operacionais e de curto prazo materializam o planejamento em longo prazo e possibilitam o alinhamento das funções dos funcionários aos objetivos estratégicos. (TAVARES, 2000). São requisitos importantes, pois "as organizações focalizadas na estratégia exigem que todos os empregados compreendam a estratégia e conduzam suas tarefas cotidianas de modo a contribuir para o seu êxito". (KAPLAN; NORTON, 2000, p. 22).

Além do alinhamento entre as instâncias estratégicas e operacionais da empresa é necessário alocar os recursos, adequar a estrutura, os processos e as pessoas, pois são fatores que decerto irão influenciar a execução estratégica. (TAVARES, 2000). Portanto, é recomendável que as ações de implementação não se limitem apenas ao desdobramento dos objetivos. (OLIVEIRA, 1991; WRIGHT et al., 2000; TAVARES, 2000; ANDREWS, 2001).

Após as fases de formulação e de implementação, os indivíduos devem se dedicar em mais um processo administrativo tradicional: o controle e avaliação. Esta etapa consiste no monitoramento do desempenho da organização, com o intuito de avaliar se os resultados propostos estão sendo atingidos, de promover o feedback e de corrigir possíveis desvios. Tais ações devem ser desempenhadas de forma contínua, uma vez que a estratégia deve ser reajustada permanentemente em ambientes dinâmicos. (ACKOFF, 1975; OLIVEIRA, 1991; RUMELT, 2001; WRIGHT et al., 2000).

Para facilitar o controle e avaliação dos resultados, é interessante associar as metas a um conjunto de indicadores de desempenho, que retratem com fidedignidade a realidade organizacional. Um bom sistema de indicadores influencia intensamente o comportamento dos indivíduos na organização. (KAPLAN; NORTON, 1997).

O acompanhamento contínuo dos parâmetros permite verificar se a organização está realmente caminhando na direção certa e se os planos ainda estão alinhados com o ambiente externo. (WRIGHT et al., 2000). Ademais, possibilita visualizar o distanciamento entre os objetivos pretendidos e o que de fato está sendo concretizado, motivando a aprendizagem organizacional. (TAVARES, 2000).

\section{METODOLOGIA}

O método de pesquisa que possibilitou a compreensão da gestão estratégica em universidades privadas foi o estudo comparativo de casos. (YIN, 2001). Este procedimento possibilitou um entendimento mais acurado de como as instituições de ensino privadas vêm se posicionando em relação à gestão estratégica, dado o nível de mudanças que se observa no ambiente educacional. Além disso, múltiplos casos conferem maior robustez ao estudo, uma vez que possibilita comparações entre os casos, bem como propiciam o entendimento do padrão de atuação das instituições em relação à administração estratégica. (YIN, 2001).

A pesquisa possui natureza qualitativa e descritiva, pois quando se busca compreender qualitativamente relações e entender um fenômeno social na sua complexidade, a abordagem qualitativa é a mais indicada. (GODOY, 1995). Além disso, permite explorar em profundidade o impacto das variáveis estudadas e obter uma visão holística do contexto. (GIL, 1991).

Estudos qualitativos abordam um contexto de vida real, no qual aconteceu uma intervenção no sentido de compreender o fenômeno ou de avaliar os resultados alcançados (SOY, 1997), constituindo-se no "principal ou mesmo o único artifício de conhecimento válido aberto a cientistas cujos interesses estão focados no comportamento humano". (BONOMA, 1985, p.5).

As principais fontes de evidências do estudo de casos são as entrevistas, os documentos, arquivos e a observação. (YIN, 2001). Para a coleta dos dados desta pesquisa, foram efetuadas 
pesquisas dos documentos e entrevistas abertas. Dentre os documentos consultados, todos disponíveis no site das universidades, estão: o estatuto, o organograma, as políticas das atividades fins e meio, bem como o resumo do plano estratégico. As entrevistas foram realizadas com o coordenador do processo de planejamento estratégico em cada instituição.

Para interpretar e avaliar os dados coletados, foi utilizada a estratégia de análise de conteúdo, com o intuito de entender mais profundamente um discurso e captar diversas percepções possíveis. (GODOY, 1995). Com vistas a facilitar tal interpretação, foram criadas categorias de análise que possuem total relação com os objetivos específicos da pesquisa. Ademais, buscou-se, na medida do possível, confrontar os dados das entrevistas com os dos documentos em um processo conhecido como triangulação, recurso usado para encontrar evidências mais fortes sobre o fenômeno em estudo. (JICK, 1979).

As categorias de análise utilizadas foram: (I) fatores indutores da gestão estratégica; (II) tempo de desenvolvimento do processo; (III) grau de centralização/descentralização; (IV) visão geral das etapas que compõem o processo formal de estratégia.

\section{RESULTADOS}

\section{Descrição da gestão estratégica do Caso A}

A aprovação do primeiro plano estratégico da Universidade A se deu em 1993 e foi resultante de um processo iniciado em 1991. Desde sua institucionalização, o processo passou por diversos ajustes e revisões periódicas (Entrevista).

Os motivos fundamentais que motivaram a Instituição A a se decidir pela realização da gestão estratégica foram a necessidades de se estabelecer uma visão de futuro e de se criar uma sistemática racional para a proposição de cenários (Entrevista).

O processo de planejamento do Caso A registrou diferentes momentos em relação ao grau de centralização/descentralização. A primeira experiência, em 1991, ocorreu de forma participativa, com envolvimento indiscriminado da comunidade no plano de futuro da instituição. Se, por um lado, o plano teve vasta adesão, por outro, mostrou-se um trabalho bastante moroso e disperso. A solução encontrada foi de centralizar o processo no momento das análises ambientais e da definição das estratégias, que passou a ser feito estritamente pela administração superior. Já na etapa de implementação dos planos foi necessário optar pela descentralização, uma vez que quem executa as ações são os profissionais da base da instituição (Entrevista).

O processo de planejamento na Universidade A se desenvolveu através das seguintes etapas: (I) análise do ambiente externo e identificação das oportunidades e ameaças; (II) análise do ambiente interno e explicitação dos pontos fortes e fracos; (III) elaboração de uma matriz que cruza as avaliações externa e interna; (IV) planejamento de cenários; (V) definição de estratégias para cada cenário. Nesta sequência, são propostos os objetivos e os indicadores de desempenho e, por fim, são definidos os programas de execução (Entrevista, Documento).

Para a definição dos objetivos e das estratégias, a Universidade A considera fundamental realizar tanto a análise externa quanto a interna. Na primeira dimensão, verificou-se que os fatores macroambientais que mais interferem no seu funcionamento são as forças legais (regulamentação do Ministério da Educação), tecnológicas (ensino a distância) e socioculturais (a obsolescência de carreiras universitárias tradicionais, em decorrência de novas exigências do mundo do trabalho e da sociedade) (Entrevista).

A análise do ambiente de tarefa na Instituição A contempla a avaliação dos diversos públicos que interferem no funcionamento da universidade, quais sejam: alunos, professores, funcionários, mantenedores, órgãos reguladores, empresas. Isto, pois, um dos seus objetivos 
estratégicos é manter um relacionamento produtivo com os diversos públicos e satisfazer plenamente as suas demandas. Ainda no contexto do ambiente de negócios, verificou-se que a intensificação da concorrência foi considerada uma das forças que tiveram maior impacto nas atividades da Universidade A (Entrevista).

No que tange à análise interna, verificou-se que a Instituição A busca conhecer as suas capacidades e limitações internas, para que os objetivos propostos possam ser atingidos. Os principais parâmetros considerados nesta etapa são: a gestão dos recursos e das atividades fins e a adequação da estrutura (Entrevista, Documento).

Para a operacionalização do conjunto de objetivos, a Instituição A desenvolve programas que detalham as ações, os recursos, o cronograma de execução e os resultados esperados. Mesmo que haja clareza quanto aos meios de execução, a universidade perpassou por algumas dificuldades, a saber: (I) resistência das pessoas em cumprir as propostas delineadas pela alta administração; (II) estrutura centralizada e processos inflexíveis; (III) receio dos indivíduos com os impactos da inovação (Entrevista, Documento).

Com o intuito de minimizar as barreiras encontradas, a Universidade A propôs que a execução seguisse uma lógica de gestão por projetos voltada para os resultados e apoiada por um sistema integrado de informações, embora não ficou evidenciado se esta solução de fato atacou os problemas de implementação (Entrevista).

Nesta sequência, para o acompanhamento dos resultados, a Instituição A associou cada objetivo a metas e a indicadores de desempenho. Os responsáveis por esse controle são os integrantes da administração superior. Através de reuniões recorrentes esses indivíduos acompanham os resultados, fazem avaliação crítica do processo e promovem as mudanças a serem incorporadas no próximo ciclo de planejamento (Entrevista).

Enfim, a última evidência importante do Caso A é que a universidade conseguiu melhorar o seu desempenho em função do desenvolvimento da gestão estratégica. Dentre os resultados positivos estão: o aprimoramento das políticas de preço, o aperfeiçoamento da gestão dos contratos, o estabelecimento de uma estrutura mais ágil, a diversificação da oferta de cursos de graduação e pós-graduação e o fechamento de parcerias com empresas em áreas de excelência.

\section{Descrição da gestão estratégica do Caso $B$}

A gestão estratégica na Instituição B é mais recente e começou a ser realizada em 2003. A motivação para o desenvolvimento desse planejamento veio da necessidade de se estabelecer uma intenção de futuro, assim como no Caso A, com o intuito de preparar a instituição para lidar com o ambiente e de melhorar a qualidade da educação superior oferecida (Entrevista, Documento).

A gestão estratégica na Instituição B guarda características de centralização, pois o coordenador do processo entende que o plano deve ser feito estritamente pela alta administração. Este planejamento se dá por meio da realização das seguintes fases: (I) realização de atividades preparatórias; (II) definição das diretrizes da mantenedora; (III) nivelamento conceitual dos participantes; (IV) desenvolvimento dos diagnósticos externo e interno; (V) proposição de cenários; (VI) formulação das estratégias, (VII) aprovação do plano pela mantenedora (Entrevista).

Depois de estabelecidas as diretrizes da mantenedora e de disseminados os conceitos de planejamento, a Universidade B se dedica na realização dos diagnósticos ambientais, etapa considerada essencial para a proposição dos objetivos institucionais. Na dimensão macroambiental, as variáveis que mais afetam as suas atividades são a político-legal (as deliberações dos órgãos governamentais) e a demográfica (redução da participação dos grupos etários mais jovens na pirâmide demográfica do Brasil) (Entrevista, Documento).

No contexto do ambiente tarefa (setor de ensino), o respondente destacou a participação incisiva do Ministério da Educação através das regulamentações exaradas por este órgão e, em decorrência, as exigências a serem cumpridas pelas Instituições.

Para uma avaliação mais precisa e sistêmica do ambiente educacional, a Instituição B busca conhecer os alunos potenciais a ingressar no ensino superior e efetua, frequentemente, 
pesquisas para a obtenção de dados deste público-alvo. Além disso, a universidade monitora as práticas e ações da concorrência (Entrevista).

Depois de realizados os diagnósticos externos, a Universidade B avalia os seus pontos fortes e fracos para a seleção de objetivos e de estratégias consistentes com suas capacidades internas. Os principais parâmetros considerados na avaliação interna são: a missão, os valores e a capacidade de alocar os recursos (Entrevista, Documento).

Nesta sequência, para a etapa de execução, a Universidade B desenvolveu um modelo denominado de gestão por projetos. Consiste no desdobramento e na tradução dos objetivos e das estratégias em programas de curto prazo, os quais possuem recursos para sua implementação (Entrevista).

Os obstáculos encontrados na fase de execução da estratégia foram: a dificuldade de utilizar um modelo ainda recente, a ausência de uma cultura adequada ao desenvolvimento do planejamento e a diversidade de formação dos participantes, o que gerava conflito de interesses, tornando a implementação lenta. Para lidar com esses impasses, a Universidade B busca estabelecer um processo de diálogo e de capacitação dos envolvidos, embora não ficou evidenciado se tais medidas conseguiram sanar os problemas de execução (Entrevista).

Com relação à estrutura organizacional, verificou-se que nenhuma alteração substancial foi feita desde 2003, ano da formalização do plano. Ou seja, constatou-se que não houve reconfiguração interna para a implementação da estratégia (Entrevista).

A despeito da manutenção da estrutura, constatou-se que houve melhoria da performance da instituição em função da gestão estratégica. Dentre as contribuições verificadas destacam-se: a melhoria da imagem institucional frente aos diversos públicos, a elevação da qualidade das atividades-fim e a expansão do ensino a distância (Entrevista, Documento).

Os projetos de execução da Instituição B são semestralmente monitorados, através de um conjunto de indicadores de desempenho, a fim de garantir o alcance dos resultados pretendidos. O setor responsável por esse controle é o Departamento de Planejamento e Organização (Entrevista).

A etapa de controle e avaliação tem auxiliado no ciclo seguinte de gestão estratégica na Universidade B. Isto, pois, baseando-se na avaliação dos resultados obtidos define-se o processo de planejamento para o próximo ano e, consequentemente, a aprovação de novos projetos (Entrevista).

\section{Descrição da gestão estratégica do Caso C}

A gestão estratégica é desenvolvida na Universidade C desde 1998. A principal razão para se desenvolver esse processo formal foi o fato de a instituição ter alcançado a categoria de Universidade. Ser "universidade" significa que além do ensino da graduação, a instituição deve, obrigatoriamente, atuar nas atividades de extensão e de pesquisa e pós-graduação, mudança que ampliou substancialmente os compromissos da Universidade C com a sociedade. Nestes termos, a instituição se viu diante de novos desafios tanto internos, quanto externos (Entrevista, Documento).

Um fato interessante é que a gestão estratégica na Instituição $C$ ainda não está consolidada e estabelecida, como nos Casos A e B. Mesmo que algumas ações nesse sentido já tenham sido empreendidas, os participantes não conseguiram constituir um processo contínuo, consistente e articulado.

Em 1998, criou-se, na Instituição C, o documento de planejamento estratégico (PE) que contemplava concepções e diretrizes para o direcionamento das decisões. Entretanto, o planejamento não estava articulado ao orçamento da universidade. Isto significa a ausência de recursos para a execução das ações, o que inviabilizou os propósitos estratégicos (Entrevista).

Uma nova tentativa foi empreendida em 2004, ano em que a instituição adotou o balanced score card (BSC), ferramenta de gerenciamento e execução da estratégia. Nesta época, foram 
elaborados mapas estratégicos que incluem objetivos e indicadores de desempenho. Poucos resultados foram obtidos através do BSC, o que levou a Universidade C a repensar tanto esta ferramenta, como o planejamento estratégico iniciado em1998. A ideia é de dar início a uma nova fase de planejamento, com a construção de uma nova visão de futuro (Entrevista).

Os participantes do PE e da construção do BSC foram: reitoria, principais gestores e alguns docentes que não possuem posição na administração superior. Até o presente momento, nenhum dos modelos propostos obteve uma continuidade ideal e nem conseguiram envolver os profissionais da base da universidade (Entrevista).

Dentro do escopo do PE na Universidade C, contatou-se que foram efetuados estudos prospectivos dos fatores macroambientais (econômico, tecnológico, político-legal, sociocultural, demográfico), sendo que o ambiente político-legal é um dos que mais interfere no funcionamento da instituição. Por exemplo, a forte pressão para adesão ao Programa Universidade para Todos (PROUNI), do governo federal, afetou diretamente a política social e filantrópica da Universidade C (Entrevista).

Já no ambiente tarefa, a Instituição C preocupa-se em monitorar o comportamento dos candidatos potenciais, bem como as ações da concorrência (Entrevista).

Além da análise do ambiente externo, a Universidade C demonstra preocupação em conhecer as suas capacidades e limitações internas para a definição dos objetivos institucionais. Entre as dimensões consideradas nesta avaliação destacam-se: as políticas gerais estabelecidas, a infraestrutura, a tecnologia e a capacidade de investimento e alocação de recursos (Entrevista).

Embora a Universidade C tenha se empenhado na elaboração de estudos do ambiente externo e interno, a implementação de estratégias não foram bem-sucedidas. A falta de entendimento de como se dá a aplicação da gestão estratégica no contexto universitário foi um dos principais motivos do resultado insatisfatório. Segundo o respondente, as mudanças no cenário de educação nacional ocorreram sem a presença de gestores educacionais capazes de lidar com as questões estratégicas. Soma-se a isso a ausência de uma cultura institucional adequada para a condução eficaz do planejamento nestas instituições (Entrevista).

Outra dificuldade observada é o fato de a Universidade $\mathrm{C}$ ser confessional e ter uma postura conservadora, mas enfrentar, no mercado, concorrentes que consideram a educação uma "mercadoria" geradora de lucro. Isto significa que muitas instituições não priorizam a qualidade do ensino, nem os compromissos com a sociedade, diferentemente da Universidade C. Por um lado, esse diferencial melhora a imagem da organização diante dos diversos públicos. Por outro, requer muita cautela, responsabilidade e um investimento substancial, o que traz complexidade ao funcionamento da Universidade C (Entrevista).

Os obstáculos descritos impediram que a gestão estratégica alcançasse uma continuidade ideal e se consolidasse, mesmo com os esforços despendidos nas análises ambientais. Ainda, assim, há um forte desejo dos envolvidos no planejamento de torná-lo uma fonte de melhorias para a universidade (Entrevista).

Enfim, a etapa de controle e avaliação dos resultados é considerada relevante pela Instituição $C$, porém não tem sido efetuada de forma rotineira. Isto em função das tentativas de formulação e implementação dos objetivos e ações terem sido ineficientes, o que paralisou o processo após as análises ambientais (Entrevista).

Em suma, os esforços de planejamento no Caso C existiram, mas se mostram dispersos e ineficazes, inviabilizando a consolidação da gestão estratégica nesta instituição.

\section{Análise comparativa dos Casos A, B e C}

Após o entendimento da gestão estratégica em cada universidade estudada, fez-se uma análise comparativa dos três casos estudados, sintetizada no quadro 1. 


\begin{tabular}{|c|c|c|c|}
\hline Categorias & Caso A & Caso B & Caso C \\
\hline $\begin{array}{l}\text { Fatores } \\
\text { indutores }\end{array}$ & $\begin{array}{l}\text { Criar visão de futuro e } \\
\text { metodologia para a } \\
\text { proposição de cenários. }\end{array}$ & $\begin{array}{l}\text { Criar visão de futuro, tendo em } \\
\text { vista às alterações ambientais. }\end{array}$ & $\begin{array}{l}\text { Mudança para a categoria de } \\
\text { Universidade, o que gerou } \\
\text { desafios internos e externos. }\end{array}$ \\
\hline $\begin{array}{c}\text { Tempo de } \\
\text { desenvolvimento }\end{array}$ & Processo iniciado em 1991. & Plano formalizado em 2003. & Criado em 1998. \\
\hline \multirow[t]{2}{*}{$\begin{array}{c}\text { Grau de } \\
\text { centralização/ } \\
\text { descentralização }\end{array}$} & $\begin{array}{l}\text { Centralizado na fase de } \\
\text { formulação estratégica, } \\
\text { porém a implementação é } \\
\text { descentralizada. }\end{array}$ & $\begin{array}{l}\text { Centralizado. Entende-se que o } \\
\text { plano deve restrito a alta- } \\
\text { administração. }\end{array}$ & $\begin{array}{l}\text { Centralizado na fase das } \\
\text { análises ambientais. Não } \\
\text { chegou a fase de execução. }\end{array}$ \\
\hline & $\begin{array}{l}\text { Análise dos ambientes } \\
\text { externo e interno; matriz } \\
\text { SWOT; desenvolvimento de } \\
\text { cenários; definição das } \\
\text { estratégias; aprovação das } \\
\text { opções estratégicas; escolha } \\
\text { dos objetivos e dos fatores } \\
\text { críticos de sucesso; definição } \\
\text { dos indicadores e dos } \\
\text { programas de execução. }\end{array}$ & $\begin{array}{l}\text { Atividades preparatórias; } \\
\text { definição das políticas; } \\
\text { nivelamento conceitual dos } \\
\text { envolvidos; análise dos } \\
\text { ambientes externo e interno; } \\
\text { desenvolvimento de cenários; } \\
\text { escolha dos objetivos; } \\
\text { formulação das estratégias; } \\
\text { aprovação da mantenedora, } \\
\text { definição dos projetos anuais. }\end{array}$ & $\begin{array}{l}\text { O processo não se consolidou } \\
\text { e as ações mostraram-se } \\
\text { desarticuladas. Tentou-se } \\
\text { desenvolver um plano } \\
\text { estratégico e depois o BSC, } \\
\text { sem resultados favoráveis. } \\
\text { Atualmente, a Instituição C } \\
\text { questiona ambos os modelos e } \\
\text { propõe a construção de nova } \\
\text { visão de futuro. }\end{array}$ \\
\hline 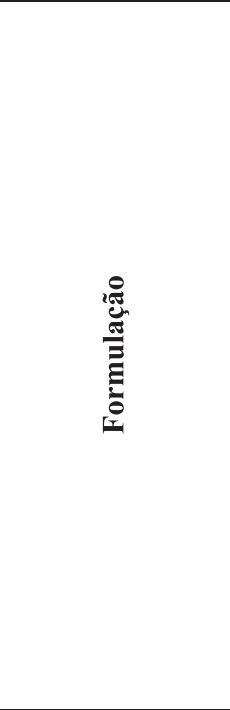 & $\begin{array}{l}\text { Análise macro ambiental: } \\
\text { Efetua tal análise, e } \\
\text { considera os fatores } \\
\text { político-legal, o tecnológico } \\
\text { e o sócio -cultural os mais } \\
\text { influentes. } \\
\text { Análise do ambiente tarefa: } \\
\text { Considera relevante analisar o } \\
\text { ambiente competitivo e } \\
\text { aponta que a legislação do } \\
\text { MEC e a concorrência são as } \\
\text { forças mais atuantes. } \\
\text { Análise interna: Preocupa-se } \\
\text { em avaliar os aspectos } \\
\text { internos. As principais } \\
\text { dimensões avaliadas são: a } \\
\text { gestão dos recursos e a } \\
\text { adequação da estrutura. }\end{array}$ & $\begin{array}{l}\text { Análise macro ambiental: } \\
\text { Efetua tal análise, e } \\
\text { considera os fatores político- } \\
\text { legal e o demográfico os mais } \\
\text { influentes. } \\
\text { Análise do ambiente tarefa: } \\
\text { Considera relevante analisar o } \\
\text { ambiente competitivo e aponta } \\
\text { que a legislação do MEC é a } \\
\text { força mais atuante. } \\
\text { Análise interna: Preocupa-se } \\
\text { em avaliar os aspectos internos. } \\
\text { As principais dimensões } \\
\text { avaliadas são: a missão, os } \\
\text { valores e a capacidade de alocar } \\
\text { os recursos. }\end{array}$ & $\begin{array}{l}\text { Análise macro ambiental: } \\
\text { Efetua tal análise, e } \\
\text { considera em alguns } \\
\text { momentos a força político- } \\
\text { legal a mais atuante. } \\
\text { Análise do ambiente tarefa: } \\
\text { Considera relevante analisar o } \\
\text { ambiente competitivo e aponta } \\
\text { que a legislação do MEC é a } \\
\text { força mais atuante. } \\
\text { Análise interna: Preocupa-se } \\
\text { em avaliar os aspectos } \\
\text { internos. As principais } \\
\text { dimensões avaliadas são: as } \\
\text { políticas gerais estabelecidas, a } \\
\text { infra-estrutura, a tecnologia e a } \\
\text { capacidade de investimento e } \\
\text { de alocar os recursos. }\end{array}$ \\
\hline 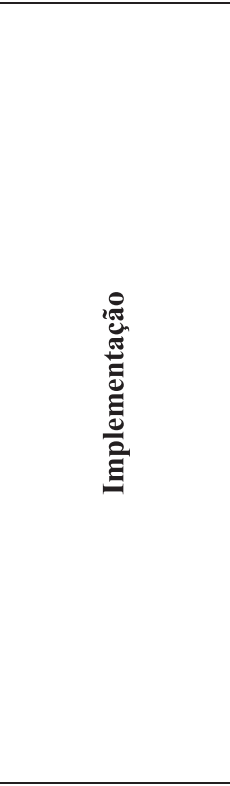 & $\begin{array}{l}\text { Formas de materializaç̃o: } \\
\text { Gestão por projetos: } \\
\text { desdobramento dos objetivos } \\
\text { em programas de curto prazo } \\
\text { que detalham as ações, os } \\
\text { meios, os recursos, o } \\
\text { cronograma e os indicadores. } \\
\text { Barreiras à implementação: } \\
\text { Resistência das pessoas em } \\
\text { cumprir as propostas; } \\
\text { estrutura centralizada e } \\
\text { processos inflexíveis; receio } \\
\text { dos indivíduos com os } \\
\text { impactos da inovação. } \\
\text { Relação planejamento e } \\
\text { performance institucional: } \\
\text { Visível esta relação, visto que } \\
\text { algumas estratégias foram } \\
\text { executadas e contribuíram } \\
\text { para o desenvolvimento } \\
\text { institucional. }\end{array}$ & $\begin{array}{l}\text { Barreiras à implementacão: } \\
\text { A ausência de uma cultura } \\
\text { adequada ao planejamento; } \\
\text { conflitos de interesses entre os } \\
\text { envolvidos; a utilização da } \\
\text { gestão por projetos ainda gerava } \\
\text { dificuldades. } \\
\text { Relação planejamento e } \\
\text { performance institucional: } \\
\text { Visível esta relação, visto que } \\
\text { algumas estratégias foram } \\
\text { executadas e contribuíram para } \\
\text { o desempenho institucional. }\end{array}$ & $\begin{array}{l}\text { Barreiras à implementacão: } \\
\text { A ausência de uma cultura } \\
\text { adequada ao planejamento; a } \\
\text { carência de profissionais } \\
\text { capacitados para a gestão de } \\
\text { universidades; o caráter } \\
\text { confessional e conservador da } \\
\text { instituição. } \\
\text { Relacão planejamento e } \\
\text { performance institucional: } \\
\text { Fraca esta relação, pois a fase } \\
\text { de implementação não foi } \\
\text { ainda bem-sucedida. }\end{array}$ \\
\hline
\end{tabular}


Continuação...

\begin{tabular}{|c|c|c|c|}
\hline Categorias & Caso A & Caso B & Caso C \\
\hline 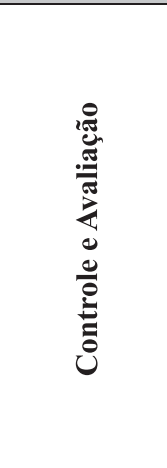 & $\begin{array}{l}\text { Formas de monitoramento: } \\
\text { Efetua o acompanhamento } \\
\text { dos resultados através de } \\
\text { metas e de indicadores de } \\
\text { desempenho. } \\
\text { Reflexo no próximo ciclo de } \\
\text { planejamento: Em reuniões } \\
\text { freqüentes, faz-se um } \\
\text { levantamento das } \\
\text { necessidades de alterações a } \\
\text { serem incorporadas no } \\
\text { próximo ciclo de } \\
\text { planejamento. }\end{array}$ & $\begin{array}{l}\text { Formas de monitoramento: } \\
\begin{array}{l}\text { Efetua o acompanhamento } \\
\text { dos resultados através de } \\
\text { indicadores de desempenho. }\end{array} \\
\text { Reflexo no próximo ciclo de } \\
\text { planejamento: Com base na } \\
\text { avaliação e nos resultado } \\
\text { obtidos, define-se o processo } \\
\text { de planejamento para o ano } \\
\text { seguinte. }\end{array}$ & $\begin{array}{l}\text { Formas de monitoramento: } \\
\text { Não efetua o } \\
\text { acompanhamento dos } \\
\text { resultados. } \\
\text { Reflexo no próximo ciclo de } \\
\begin{array}{l}\text { planejamento: Como não há } \\
\text { acompanhamento, não há } \\
\text { mudanças no próximo ciclo. }\end{array}\end{array}$ \\
\hline
\end{tabular}

Quadro 1 - Processo de Gestão Estratégica das Universidades A, B, C

Fonte: Dados primários da pesquisa

\section{CONCLUSÕES}

As três universidades estudadas consideram fundamental desenvolver a gestão estratégica tanto para a criação de uma visão de futuro, quanto para enfrentarem com maior segurança os desafios ambientais. A teoria da administração estratégica confirma a premissa das universidades, ou seja, a GE de fato possibilita a construção de uma intenção de futuro e a consequente condução dos esforços organizacionais nesta trajetória (ACKOFF, 1975; TAVARES, 2000; ANDREWS, 2001) e, ainda, prepara a instituição para responder de maneira mais consistente às dinâmicas ambientais. (ACKOFF, 1975; ANDREWS, 2001).

Embora os dirigentes reconheçam a importância do processo formal de estratégia, há ainda uma série de obstáculos a serem suplantados para o alcance dos resultados desejáveis. Fatores como estrutura, liderança, cultura, sistemas e recursos, se não adequados, tornam-se certamente barreiras à operacionalização estratégica. (OLIVEIRA, 1991; WRIGHT et al., 2000; TAVARES, 2000; ANDREWS, 2001).

Nas Instituições A e B, a gestão estratégica é um processo consolidado e contínuo. Isto pode ser relacionado com o tempo de desenvolvimento do planejamento na Universidade A, mas não no caso B, que formalizou o seu plano mais recentemente, apenas em 2003. Já a Universidade C, embora tenha iniciado a GE em 1998, ainda não conseguiu estabelecer um processo contínuo e sólido. Os esforços e tentativas em termos de análises ambientais tem sido constantes, no entanto, é fato que a estratégia fracassa se não for eficientemente implementada. (ANDREWS, 2001; KAPLAN; NORTON, 2000; WRIGHT et al., 2000).

Com relação ao grau de envolvimento da comunidade acadêmica, contatou-se que o processo tende a ser centralizado nos três objetos de estudo. Isto ocorre, sobretudo, na fase de formulação, que consiste na elaboração de análises ambientais e na definição dos objetivos e das estratégias. Já na etapa da implementação dos planos, há indícios de descentralização das atividades no Caso A, uma vez que a alta administração envolveu os profissionais da base das universidades para a execução das propostas.

Nestes termos, o processo na Instituição A é conduzido da seguinte maneira: a administração superior exara orientações e diretrizes gerais para as demais instâncias organizacionais alinharem as suas funções com os objetivos estratégicos. A descentralização na etapa de execu- 
ção é fundamental, haja vista que um planejamento bem conduzido demanda que todos conheçam a estratégia e contribuam para a sua excelência. (KAPLAN; NORTON, 2000).

A gestão estratégica é um processo composto em fases claramente delineadas e sequenciais (OLIVEIRA, 1991; WRIGHT et al., 2000; ANDREWS, 2001), sendo que, nos casos A e B, as etapas da GE seguem, de maneira geral, a lógica proposta pela literatura, qual seja: realização de diagnósticos ambientais (externo e interno), desenvolvimento da missão, estabelecimento de objetivos e estratégias, definição de programas de execução e monitoramento sistemático dos resultados. (TAVARES, 2000).

Com relação à avaliação ambiental, contatou-se que a mudança constante na legislação educacional, a participação incisiva do Ministério da Educação na fiscalização das atividades universitárias e os públicos relevantes (discentes, docentes e concorrentes) foram considerados forças determinantes do funcionamento das universidades. Assim, sendo, são variáveis que merecem muita atenção no momento de definição dos objetivos e das estratégias institucionais, mesmo porque não há como escapar da influência do ambiente. De fato, ele intervém decisivamente na maneira como as instituições se organizam. (BURNS; STALKER, 1961; LAWRENCE; LORSCH, 1973; THOMPSON, 1967).

A análise intraorganizacional, que consiste na competência interna em aproveitar as oportunidades e neutralizar as ameaças externas (ANDREWS, 2001; TAVARES; 2000), também foi considerada fundamental pelas universidades para a formulação da estratégia. Nestes termos, a variável interna mencionada pelas três universidades foi a capacidade institucional na gestão e alocação dos recursos.

A etapa de implementação estratégica nas Universidades A e B se dá por meio dos desdobramentos dos planos estratégicos em programas e projetos de curto prazo. Segundo Tavares (2000), se a execução não for bem-sucedida todos os esforços na formulação se perdem e os objetivos propostos não são atingidos. Exemplo disso é a Universidade C, que desenvolveu análises ambientais, mas não conseguiu dar continuidade ao processo, comprometendo os resultados pretendidos. Ou seja, a estratégia pode fracassar se não for bem operacionalizada (WRIGHT et al., 2000; ANDREWS, 2001), diferentemente das Instituições A e B, que conduziram a implementação de maneira eficaz, sendo possível visualizar uma relação factível entre planejamento e melhoria do desempenho institucional.

Dentre as dificuldades mais encontradas na fase de execução podem-se citar: uma estrutura inapropriada, a ausência de recursos direcionados ao alcance das metas e a resistência dos indivíduos em cumprirem os objetivos propostos pela direção superior. (OLIVEIRA, 1991; WRIGHT et al., 2000; TAVARES, 2000; ANDREWS, 2001). Enquanto a Instituição A procurou ajustar a estrutura, os recursos e a cultura, a B falhou na adequação do primeiro fator. Ou seja, não ocorreu alteração do arranjo organizacional para a implementação da estratégia no caso B. Já na Universidade C, além da resistência institucional, observou-se que a sua natureza confessional e a carência de gestores educacionais capazes de lidar com as questões estratégicas representaram empecilhos à fase de operacionalização estratégica.

Após elaborar e implementar a estratégia é primordial controlar o seu andamento, haja vista que a estratégia deve ser reajustada permanentemente em ambientes dinâmicos. (ACKOFF, 1975; OLIVEIRA, 1991; RUMELT, 2001; WRIGHT et al., 2000). As três universidades consideraram importante efetuar o controle e avaliação dos resultados, embora somente as Instituições A e B efetuem este monitoramento de maneira sistemática. Nestes termos, os indicadores de desempenho são instrumentos fundamentais. Ou seja, um bom sistema de indicadores, além de propiciar o controle dos resultados, influencia o comportamento dos indivíduos na organização. (KAPLAN; NORTON, 1997). 
Enfim, os casos A e B consideram importante a realização do feedback, que consiste na realimentação do processo tendo em vista a experiência adquirida. Nessas instituições os conhecimentos apreendidos no primeiro ciclo de planejamento geram insights fundamentais para o próximo período, promovendo o contínuo aperfeiçoamento do processo. Isto incrementa a aprendizagem organizacional tão fundamental em ambientes dinâmicos. (KAPLAN; NORTON, 1997; TAVARES, 2000).

\section{LIMITAÇÕES E RECOMENDAÇÕES DE ESTUDO}

As limitações desta pesquisa estão relacionadas à amostra dos respondentes e aos métodos de coleta dos dados. Primeiramente, a realização da entrevista apenas com o coordenador da gestão estratégica em cada universidade, embora capte a percepção do individuo que possui a visão global do planejamento, limita o entendimento do processo sob um único ponto de vista.

Outra limitação deste estudo refere-se à pesquisa documental, que abarcou somente os documentos disponíveis nos sites das instituições. Esse procedimento restringiu a quantidade de informações captadas, bem como afetou negativamente o nível de profundidade e qualidade das mesmas. Além disso, ao tentar captar o fenômeno da gestão estratégica em sua totalidade, a entrevista perdeu em detalhamento e especificidades.

Com relação à possibilidade de novos estudos a partir deste, sugere-se aprofundar em pesquisas que investiguem o surgimento de estratégias emergentes, empreendidas pelos profissionais da base das universidades e a sua incorporação ao planejamento deliberado. Outra frente promissora de pesquisa pode ser o conflito entre determinadas posições ou filosofias (universidades confessionais e filantrópicas) e a necessidade de adoção de uma postura mais agressiva pelas instituições, para competirem em um mercado de educação cada vez mais dinâmico e concorrido. Outro tema interessante é a questão política no âmbito da universidade, envolvendo negociações, conflitos de interesses e pontos de vista colidentes, uma vez que tal instituição abarca profissionais das mais variadas áreas de conhecimento, lutando por diversos objetivos institucionais e pessoais.

\section{REFERÊNCIAS BIBLIOGRÁFICAS}

ACKOFF, Russell Lincoln. Planejamento empresarial. Rio de Janeiro: Livros Técnicos e Científicos, 1975. 114p.

ANDREWS, Kenneth R. O conceito de estratégia empresarial. In: MINTZBERG, Henry; QUINN, James Brian. O processo da estratégia. 3. ed. Porto Alegre: Bookman, 2001. p. 58-64.

ANSOFF, H. Igor. Administração estratégica. São Paulo: Atlas, 1983. 214p.

ANSOFF, H. Igor; MCDONNELL, Edward J. Implantando a administração estratégica. 2. ed. São Paulo: Atlas, 1993. 590p.
BAUM, Joel A.C. Ecologia organizacional. In: CALDAS, Miguel; FACHIN, Roberto; FISHER, Tânia (Org.). Handbook de estudos organizacionais. São Paulo: Atlas, 1998. cap. 3, p.135-193.

BERTUCCI, Janete Lara de Oliveira. Performance organizacional em instituições de ensino superior: as PUCs brasileiras em busca de efetividade. 2000. 393f. Tese (Doutorado em Administração)Universidade Federal de Minas Gerais, Faculdade de Ciências Econômicas, Centro de Pós- Graduação e Pesquisas em Administração, Belo Horizonte, 2000.

BONOMA, Thomas V. Case research in marketing: opportunities, problems, and a process. Journal of Marketing Research, v. XXII, 1985. 
BURNS, T.; STALKER, G.M. The management of innovation. Londres: Tavistock Public, 1961.

CHANDLER, Alfred D. Strategy and structure. Cambridge: MIT Press, 1962.

EMERY, F.E.; TRIST, E.L. The casual texture of organization environments. Human Relations, v.18, p.21-32, Feb. 1965.

GIL, Antônio Carlos. Como elaborar projetos de pesquisa. 3. ed. São Paulo: Atlas, 1991. 159p.

GODOY, Arilda Schmidt. Pesquisa qualitativa: tipos fundamentais. Revista de Administração de Empresas, São Paulo, v. 35, n.3, p.20-29, maio 1995.

JICK, Todd D. Mixing qualitative and quantitative methods: triangulation in action. Cornell University. Administrative Science Quarterly, v. 24, p.602611, 1979.

KAPLAN, Robert S.; NORTON, David P. A estratégia em ação. 20. ed. Rio de Janeiro: Elsevier; Campus, 1997. 344p.

KAPLAN, Robert S. e NORTON, David P. Organização orientada para a estratégia: como as empresas que adotam o balanced scorecard prosperam no novo ambiente de negócio. Rio de Janeiro: Campus, 2000.

LAWRENCE, P. R.; LORSCH, J. W. As empresas e o ambiente: diferenciação e integração administrativas. Petrópolis: Vozes, 1973.

MILLIKEN. Franes J. Tree type of perceived uncertainty about the environment: state, effect and response uncertainty. Acadamy of Management Review, v. 12 , n.1, p. 133-143, 1987.

MINTZBERG, Henry. Os 5 p's da estratégia. In: MINTZBERG, Henry; QUINN, James Brian. O processo da estratégia. 3. ed. Porto Alegre: Bookman, 2001. p. 26-32.

MINTZBERG, Henry; AHLSTRAND, Bruce W.; LAMPEL, Joseph. Safári de estratégia: um roteiro pela selva do planejamento estratégico. Porto Alegre: Bookman, 2000. 299p.

MOTTA, Paulo Roberto. Gestão contemporânea: a ciência e a arte de ser dirigente. 13. ed. Rio de Janeiro: Record, 2002. 256p.
OLIVEIRA, Djalma de Pinho Rebouças de. Estratégia empresarial: uma abordagem empreendedora. 2. ed. rev. e atualizada São Paulo: Atlas, 1991. 381p.

Planejamento estratégico: conceitos, metodologia e praticas. 7. ed. atual. ampl. São Paulo: Atlas, 1993

PORTER, Michael E. Como as forças competitivas moldam a estratégia. In: MINTZBERG, Henry; QUINN, James Brian. O processo da estratégia. 3. ed. Porto Alegre: Bookman, 2001. p.82-89.

QUINN, James Brian. Estratégias para mudanças. In: MINTZBERG, Henry; QUINN, James Brian. O processo da estratégia. 3. ed. Porto Alegre: Bookman, 2001. p. 20-26.

QUINN, James Brian; VOYER, John. Incrementação lógica: administrando a formação da estratégia. In: MINTZBERG, Henry; QUINN, James Brian. O processo da estratégia. 3. ed. Porto Alegre: Bookman, 2001. p. 109-114.

RUMELT, Richard R. Avaliando a estratégia dos negócios. In: MINTZBERG, Henry; QUINN, James Brian. O processo da estratégia. 3. ed. Porto Alegre: Bookman, 2001. p. 64-72.

SOY, Susan K. The case study as a research method. University of Texas. 1997. Disponível em: <http:// www.gslis.utexas.edu? ssoy/useusers/ 1391d1b.htm >. Acesso em: 08 ago. 2005.

TACHIZAWA, Takeshi; ANDRADE, Rui Otávio Bernardes de. Gestão de instituições de Ensino. 4. ed. Rio de Janeiro: FGV, 2006. 288 p.

TAVARES, Mauro Calixta. Gestão estratégica. São Paulo: Atlas, 2000. 398p.

THOMPSON, J. D. Organization in action. New York: McGraw-Hill, 1967.

WRIGHT, Peter L.; KROLL, Mark J.; PARNELL, John A. Administração estratégica: conceitos. São Paulo: Atlas, 2000. 433p.

YIN, Robert K. Estudo de caso: planejamento e métodos. 3. ed. Porto Alegre: Bookman, 2005. 212 p. 